\title{
Referring physician perceptions of picture archive and communication systems
}

\author{
Authors: \\ Ryno Schoeman ${ }^{1}$ \\ Nicky Mostert-Phipps ${ }^{1}$ \\ Affiliations: \\ ${ }^{1}$ Department of Information \\ Technology, Nelson Mandela \\ Metropolitan University, \\ South Africa \\ Correspondence to: \\ Nicky Mostert-Phipps \\ Email: \\ nicky.mostert@nmmu.ac.za \\ Postal address: \\ PO Box 77000, Port Elizabeth \\ 6031, South Africa \\ Dates: \\ Received: 06 Feb. 2015 \\ Accepted: 14 May 2015 \\ Published: 20 Nov. 2015 \\ How to cite this article: \\ Schoeman, R. \& Mostert- \\ Phipps, N. Referring \\ physician perceptions \\ of picture archive and \\ communication systems. \\ S Afr J Rad. 2015;19(1); Art. \\ \#790, 5 pages. http://dx.doi. \\ org/10.4102/sajr.v19i1.790

\section{Copyright:} \\ (C) 2015. The Authors. \\ Licensee: AOSIS \\ OpenJournals. This work is \\ licensed under the Creative \\ Commons Attribution \\ License.
}

Read online:
The picture archive and communication system (PACS) is a digital radiographic system that is steadily replacing the older film-based radiographic records. Despite the various benefits associated with PACS implementation, it is not yet clear what referring physicians think of such systems. This article reviews their thoughts and perceptions, which were obtained via surveys that were completed by referring physicians with practices at private hospitals in Port Elizabeth. A critical analysis of the data collected indicated that most referring physicians perceive PACS to be beneficial.

\section{Introduction}

A picture archive and communication system (PACS) is an information system that manages the storage, distribution and viewing of digital radiography images. ${ }^{1}$ Amongst the many benefits associated with PACS is an improved image-management process via an enhanced system. The benefits of this system are: ${ }^{2}$

- better administration of imaging examination requests

- enhanced performance of imaging examinations

- enhanced distribution of images and reports

- improved archiving of imaging examinations

- more secure archiving of results

- easier retrieval of previous examinations and results.

PACS increases the productivity of radiologists and technologists, and holds many benefits for referring physicians. ${ }^{3}$ The perceptions of referring physicians regarding PACS is important in order to improve acceptance rates when introducing PACS. ${ }^{4}$

Little research has been devoted to the perceptions of South African referring physicians of PACS implementation. The primary objective of this article is to investigate the perceptions of referring physicians regarding PACS.

\section{Research method and design Instrument design}

The study was designed as an observational study to determine a cross-sectional view of referring physician perceptions regarding the benefits and drawbacks associated with PACS. A survey was selected as the appropriate data collection instrument to investigate such perceptions. A literature review was conducted to identify the benefits, as well as any drawbacks, associated with PACS. These benefits and drawbacks were developed into statements, and the participants were asked to indicate their level of agreement with these statements. The participants were able to indicate their level of agreement as: strongly agree, agree, neutral, disagree, or strongly disagree.

The statements in the survey can be categorised as they relate to communication, access, speed and the diagnostically related benefits, as well as the drawbacks associated with PACS.

The survey also included open-ended questions regarding participant introduction to PACS; the training they had received in its use; and their views on PACS versus traditional film based radiological systems.

\section{Setting}

Convenience sampling of those referring physicians who have consultation rooms at three private hospitals in Port Elizabeth (Eastern Cape Province, South Africa) yielded a sample of 96 referring physicians. 


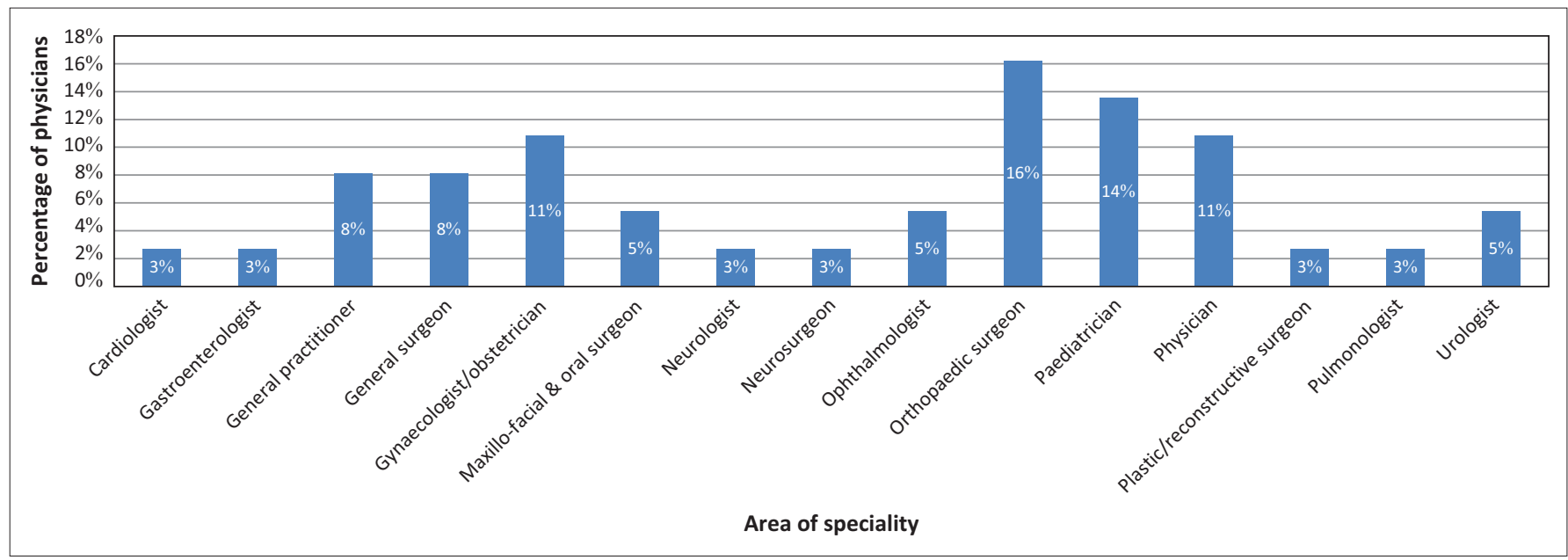

FIGURE 1: Participant speciality.

\section{Data collection}

Survey forms were delivered to the receptionists of the 96 identified referring physicians, with a request to hand the surveys to the physicians to complete. Eighty-eight forms were accepted, while eight receptionists indicated that the physician would not be willing to participate in the study, or was not available. A covering letter included information related to the purpose of the study, as well as contact details of the research team.

The surveys were left at each practice for approximately three weeks, to allow physicians sufficient time to complete them. The data was collected during August 2014.

\section{Data analysis}

Data from completed surveys was captured in a spreadsheet for analysis. The response from each participant was placed in a row, together with the results of each closed-ended question placed in a separate column. The percentages of the level of agreement for each statement were then calculated.

\section{Ethical considerations}

Participation was voluntary and anonymous. No information was gathered to identify the individual referring physicians. The mere completion of the survey indicated an informed consent to participate in the study. The necessary institutional ethical clearance was obtained from the Nelson Mandela Metropolitan University before distributing the surveys.

\section{Results and discussion}

Of the 88 surveys handed out, 37 completed surveys were returned, yielding a response rate of $42 \%$. Figures 1-2 indicate the area of speciality and age distributions of the participants.

Figure 3 indicates the comfort levels of participants in using technology such as PCs, laptops and tablets, as well as how easily they were able to navigate the Internet. Participants

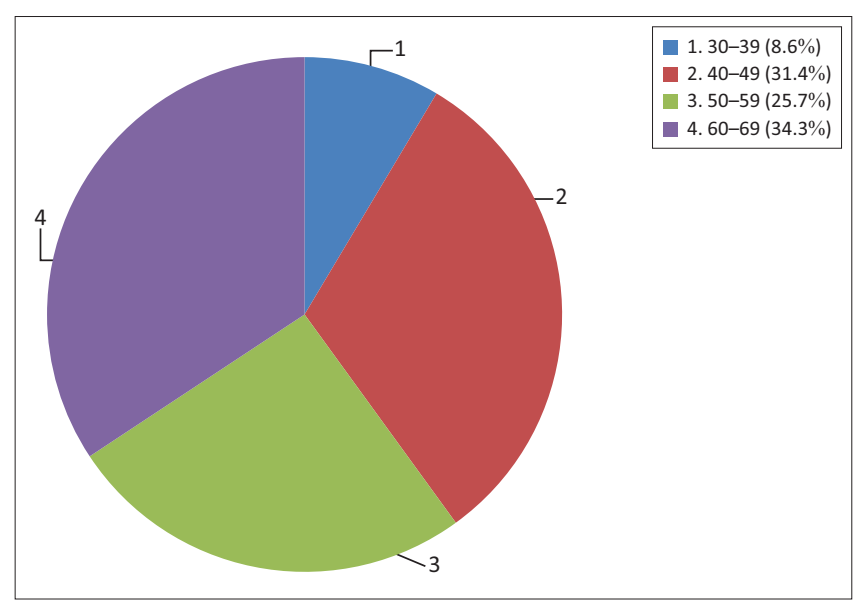

FIGURE 2: Participant age range.

were asked to indicate their response to these questions on a rating scale from 0 to 5 , with 5 indicating that they were extremely comfortable and 0 indicating that they were not at all comfortable.

Table 1 indicates the results as they relate to referring physicians perceptions of PACs

When reference to specific statements is made refer to Table 1.

\section{Communication benefits}

$89.2 \%$ of the participants strongly agree to agree that communication with other physicians is improved (Statement 1); while $59.4 \%$ of participants indicated that they strongly agree to agree that communication with the radiology department is considerably improved with PACS (Statement 2).

The greatest improvement in communication relates to communication with other physicians; this is improved by the ease of multi-site viewing (Statement 1) which allows any physician to view any image on the system - provided they can access the Web. ${ }^{5}$ A total of $62.2 \%$ strongly agreed, while $27 \%$ agreed, that this is a benefit. 


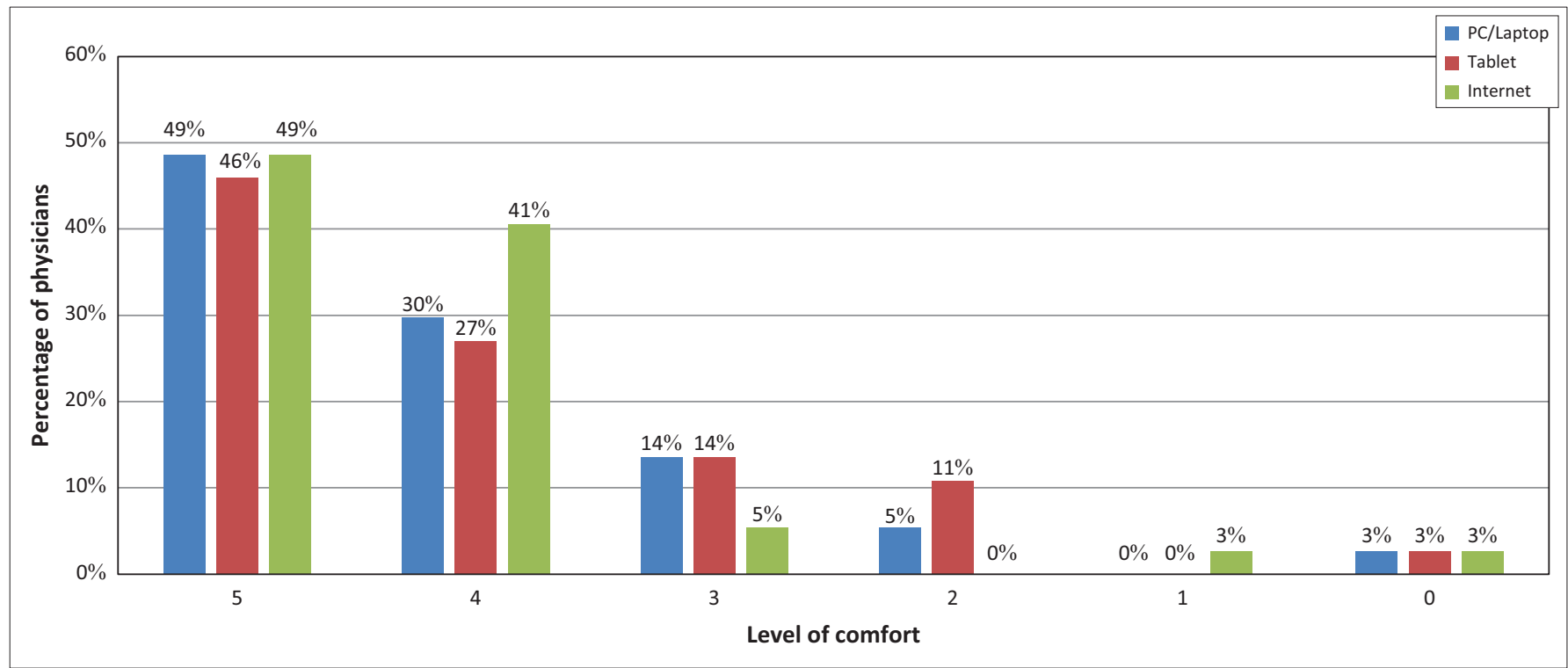

FIGURE 3: Participant comfort levels in the use of technology.

TABLE 1: Survey results.

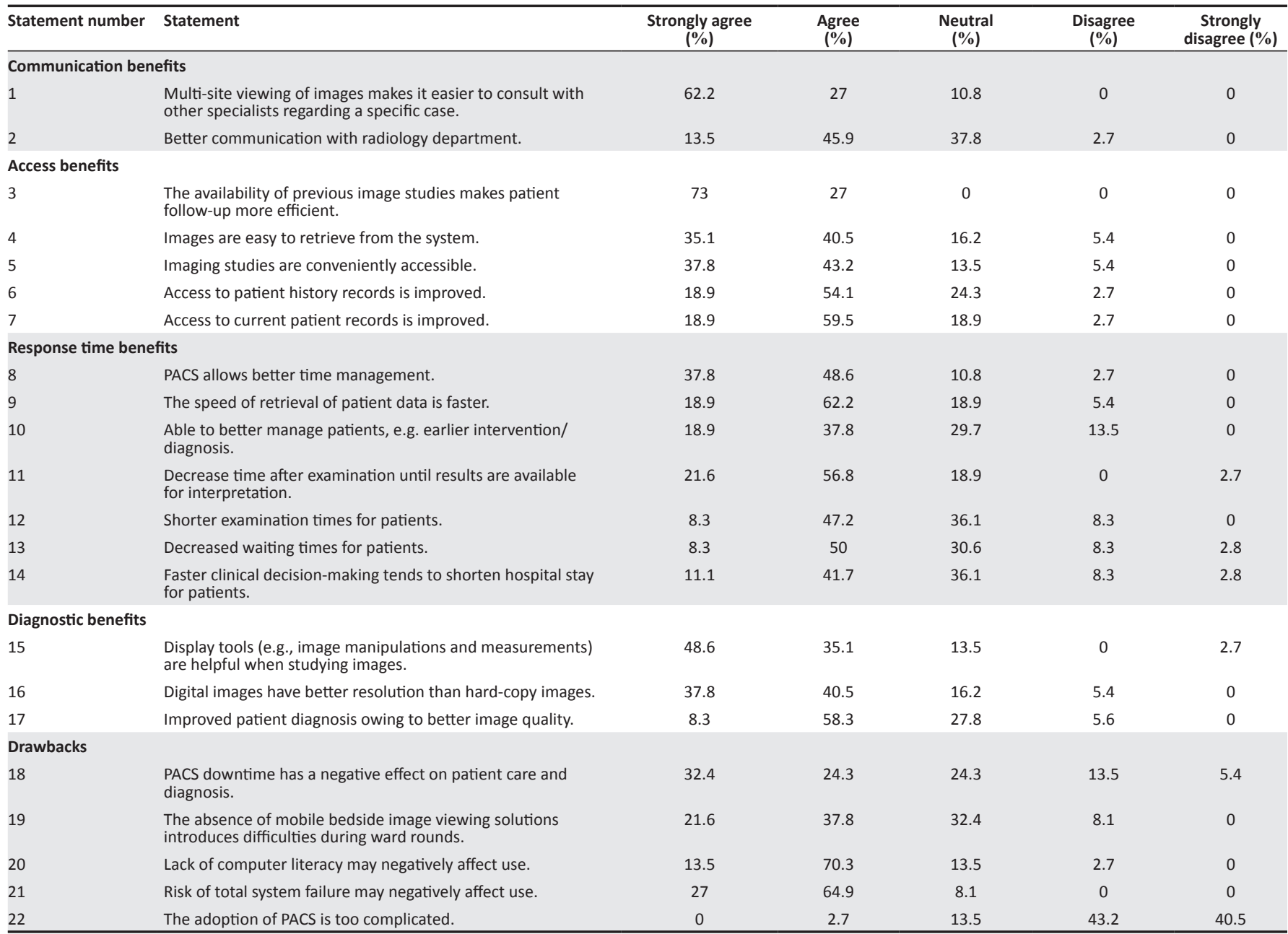

\section{Access benefits}

This includes easier access to patients' current and previous images, the ease of retrieving them, and accessibility. PACS can be accessed at a diagnostic workstation or remotely via a webpage. ${ }^{3}$
From the survey results, the access benefit that participants found the most useful seems to relate to the availability of previous imaging studies, which makes patient follow-up more efficient (Statement 3). All participants agreed with this statement (73\% strongly agreed and $27 \%$ agreed). This may 
be because, prior to PACS, film had to be stored in a storage room and, because of the large number of images made per day, the quantity of film in storage became large and caused numerous problems such as loss of information, cost of storage, and delayed clinical decision-making. ${ }^{2}$

Some participants commented in the open-ended questions that they disliked the storage of X-rays (film), and that housing the envelopes became problematic.

The survey results also indicate that there was an improvement in access to current and historical patients' records (Statements 6-7).

\section{Response time benefits}

Most referring physicians agreed that, when using PACS, the benefits include faster retrieval of patient data and images, and faster clinical decision-making. The response rate overall is much faster than film-based systems, as demonstrated by various studies., ${ }^{3,6}$ Consequently, examination and waiting times for patients are reduced, as indicated by the responses to statements 12-13. Waiting time is decreased because examination results are available for interpretation much sooner than with traditional filmbased systems. This finding is confirmed by the responses to Statement 11.

\section{Diagnostic benefits}

Before PACS, film images were used for diagnosing many patients' conditions. No specialised tools such as magnification, panning or zooming were available. On occasion, patients had to be sent back for re-examination. As seen in the results relating to diagnostic benefits in Table 1, participants agreed that PACS plays a major role in improving the diagnosis of patients.

The image can be manipulated using different sets of specialised tools, thus allowing more accurate decisions. Common tools include window width/level, tools that control the range of image pixel values displayed on the monitor; measurement tools that allow measurements to be made on the image; magnifying, panning and zooming. ${ }^{7}$

The number of participants who disagreed with, or who indicated a neutral response to, Statement 15 which relates to the tools used in diagnoses, may relate to a lack of training on how to use the PACS system. In one of the open-ended questions in the survey related to training, $14(37.8 \%)$ of the 37 participants indicated that they had received insufficient training, and that learning more about the various features offered by the PACS system would be beneficial to them.

\section{Drawbacks}

To investigate the level of agreement of the referring physicians on drawbacks associated with PACS, the participants were asked in Statement 22 if they felt that the adoption of PACS was too complicated. Only $2.7 \%$ agreed with this statement, while $13.5 \%$ were neutral. The rest disagreed and strongly disagreed with this statement; for the majority, therefore, it may be confidently said that complication was not a drawback with PACS. The results for other drawbacks are shown in Table 1.

With all the mentioned benefits related to access, there were unfortunately two major drawbacks concerning image access; many physicians commented on this issue. The first was the absence of bedside mobile imaging in the ward (Statement 19). Previously, film-based images could easily be shown to a patient and to other members of the care team in the ward. As many as $21.6 \%$ of participants strongly agreed, and $37.8 \%$ agreed, that the absence of bedside mobile image viewing in the ward introduced difficulties. Many of the physicians also commented that this was a big problem in one of the open-ended questions.

The other disadvantage raised by two doctors in the openended section of the questionnaire was confidentiality of patients' data and images. They were concerned that any physicians who could access the PACS system could view any patients' data. It may be seen that most of the physicians agreed with the drawbacks of PACS but felt that the benefits outweighed the drawbacks. Accordingly, 32 of the 37 referring physicians responded that they preferred PACS in one of the open-ended questions of the survey.

\section{Study limitations}

The generalisability of the results of the present study is limited, as the study was conducted in a specific geographical region. Despite the good response rate, the sample size was relatively small.

\section{Conclusion}

The aim of the study was to investigate referring physicians' perceptions of PACS, as well as the related benefits and drawbacks. From the survey results, it became clear that while numerous benefits are realised via PACS, some issues still require attention.

\section{Acknowledgements}

The financial assistance of the South African National Research Foundation (NRF) in this research is hereby acknowledged. The opinions expressed and the conclusions drawn are those of the authors, and are not necessarily attributable to the NRF.

\section{Competing interests}

The authors declare that they have no financial or personal relationships which may have inappropriately influenced them in writing this article. 


\section{Authors' contributions}

R.S. (Nelson Mandela Metropolitan University) contributed to the study design, data collection and analysis, writing and planning of the article draft and final version. N.M. (Nelson Mandela Metropolitan University) contributed to the study design, study coordination, review of the article draft and final version.

\section{References}

1. Schulze OC, Greyling J, Heys M, Andronikou S. Talking PACS: Part 1 - What is PACS? S Afr J Radiol. 2007;11:50-53.
2. Schulze OC, Ackermann C, Greyling J, Viljoen H, Andronikou S. Talking PACS: Part 2-Why should we change to PACS? S Afr J Rad. 2007;11:86-90. http://dx.doi. org/10.4102/sajr.v11i4.19

3. Honeyman-Buck J. PACS adoption. Semin Roentgenol. 2003;38:256-269. http:// dx.doi.org/10.1016/S0037-198X(03)00045-2

4. Pynoo B, Devolder P, Duyck W, Sijnave B, Duyck P. Do hospitals physicians' attitudes change during PACS implementation? Int J Med Inf. 2012;81:88-97. http://dx.doi.org/10.1016/j.ijmedinf.2011.10.007

5. Benjamin $M$, Aradi $Y$, Shreiber R. From shared data to sharing workflow: Merging PACS and teleradiology. Eur J Radiol. 2010;73:3-9. http://dx.doi.org/10.1016/j ejrad.2009.10.014

6. Mariani C, Tronchi A, Oncini L, Pirani O, Murri R. Analysis of the x-ray work flow in two diagnostic imaging departments with and without a RIS/PACS system. J Digit Imaging. 2006;19:18-28. http://dx.doi.org/10.1007/s10278-006-0858-3

7. Kerr C, Turner J. PACS workstation software [homepage on the Internet]. [cited 2015 Apr 2]. Available from http://www.ninestepstougly.com/pacsnet.org.uk/ Presentations\&Posters/WorkstaWork_web.pdf 